\title{
Application of Public Domain Satellite-Based DEMs in Natural Hazard Modeling
}

\author{
Abolghasem Akbari, Noram Irwin Bin Ramli, and Ngien Su Kong
}

\begin{abstract}
With the invention of Geospatial Information Systems (GIS) and Natural hazard computer models, the role of digital elevation model (DEM) has become very important and effective tools in Geohazard modeling. Flood inundation mapping, landslide susceptibility mapping and wind velocity mapping are examples that effectively employ the DEM and its derivatives as one of the important modeling inputs. On the other hand, satellite based DEMs have been growing rapidly in recent years. There are several sources of DEMs available ranging from very coarse to high resolution which provides geospatial data in different scales. This paper describe the specification and applications of public domain satellite-based DEMs including SRTM and ASTER-GDEM which, are globally free. From several applications, the scope is limited to the application of public domain satellite DEMs in flood potential mapping which is considered a widespread Geohazard. From the result, it was found that several advantages were recognized for public domain satellite-based DEMs including ease of accessibility, elimination of institutional bureaucracy, unlimited coverage, adequate spatial resolution, and more importantly, they are available free of charge.
\end{abstract}

Index Terms-DEM, SRTM, ASTER-GDEM, natural hazard.

\section{INTRODUCTION}

A hazard is defined as "a potentially damaging physical event, phenomenon or human activity that may cause the loss of life or injury, property damage, social and economic disruption or environmental degradation". This event has a probability of occurrence within a specified period of time and within a given area, and has a given intensity [1]. Hazards can be single, sequential or combined in their origin and effects. Each hazard is characterised by its location, area affected, intensity, speed, duration and frequency [2]. Natural hazards are natural processes or phenomena in the earth's system (lithosphere, hydrosphere, biosphere or atmosphere) that may constitute a damaging event [2]. A subdivision of natural hazards relates to the main controlling factors of the hazards leading to a disaster. They may be hydro-meteorological (including floods and wave surges, storms, droughts and related disasters such as extreme temperatures and forest/scrub fires, landslides and snow avalanches), geophysical hazards (resulting from anomalies in the earth's surface or subsurface, such as earthquakes, tsunamis and volcanic eruptions), or biological hazards [2] The aim of this study is to explore the advantage of public

Manuscript received July 28, 2014; revised May 13, 2015.

The authors are with the Faculty of Civil Engineering and Earth Resources, University Malaysia Pahang, Kuantan 26300, Kuantan, Malaysia (e-mail: akbari@ump.edu.my). domain satellite-based elevation data for flood potential mapping which is one of the most serious Geohazard in many countries.

\section{Digital Elevation Model}

With the invention of Geospatial Information Systems (GIS) and Geohazard computer models, the role of digital terrain model (DTM) or digital elevation model (DEM) has become very important and effective tools in analytical Geohazard studies. The DTM is defined as a numerical representation of the terrain. Since Miller and Laflamme [3] who coined the original term, other expressions such as DEM, digital height models (DHM), digital surface model (DSM), digital ground models (DGM) and digital terrain elevation model (DTEM) have been used by Maidment [4], Djokic and Ye [5], Vieux [6] and Li et al. [7]. These terms originated from different countries. According to Li et al. [7] the word DEM is widely used in United States, DHM in Germany, DGM in the United Kingdom and DTEM was introduced and is used by united states geological survey (USGS) as well as and the Defence Mapping Agency (DMA). In hydrology and flood modelling, applications of DEM are mainly focused on automate watershed boundary delineation and segmentation, definition of drainage divides, identification of flow length, flow direction and flow accumulation as well as flood inundation depth and areas. In distributed hydrological models, DEM plays a very important role. The DEM and its derivatives including slope, aspect, upslope contributing area, watershed area and curvature are important factors [8] for flood modeling and landslide susceptibility mapping. One of the key characteristic of the DEM is the cell size or DEM resolution. Many researches have carried out to find best suitable DEM cell size for different purposes and different scales. A comprehensive study by Maidment [9] have shown that DEM resolution for rainfall-runoff and flood modeling changes by watershed area (see Table I).

In theory, the DEM resolution should be selected as a function of the land surface features, scale of the process that are modeled, and numerical model used to model process [10]. But in practice the selection of DEM is often driven by data availability, judgment, test applications, experience and, last but not least, cost [11]. Traditionally, DEM has been generated from digital topographic contour lines or mass points. These methods are still used in some projects. There are some disadvantages for DEM generation based on cartographic products. Non-homogeneity of topographic maps, institutional bureaucracy for accessing the data, edge matching error, dead end and code consistency are the main sources of errors in the traditional method of DEM generation. 
Some of these errors are demonstrated in real data collected from the Department of Survey and Mapping Malaysia. For accurate analysis of Geohazards such as flood inundation areas or mass movement, airborne laser technology LiDAR, IfSAR, IKONOS and Spot DEM have been used in several projects. However these technologies are expensive and not accessible for use in all projects.

TABLE I: RECOMMENDED DEM CELL SIZES AND THEIR RANGE OF APPLICATIONS (AFTER MAIDMENT [9])

\begin{tabular}{|c||l||l||}
\hline Cell Size & Watershed Area $\left(\mathrm{km}^{2}\right)$ & Typical Application \\
\hline \hline $30 \mathrm{~m}$ & 5 & Urban watersheds \\
\hline \hline $90 \mathrm{~m}$ & 40 & Rural watersheds \\
\hline \hline $460 \mathrm{~m}$ & 1000 & River basins \\
\hline $930 \mathrm{~m}$ & 4000 & Nations \\
\hline \hline $5.6 \mathrm{~km}$ & 150,000 & Continents \\
\hline \hline $9.3 \mathrm{~km}$ & 400,000 & Global \\
\hline \hline
\end{tabular}

\section{Public Domain SATEllite DEMs}

The Shuttle Topography Mission (SRTM) elevation data is the first global free satellite DEM released in 2003. The SRTM elevation data have been produced using radar images gathered from the National Aeronautics and Space Administration's shuttle (NASA). The SRTM provides an accurate global elevation model with a vertical accuracy of 6 $\mathrm{m}$ and a horizontal pixel spacing of $30 \mathrm{~m}$ over the USA and Canada and $90 \mathrm{~m}$ outside these regions [12]. NASA released the SRTM dataset in 2003. The SRTM elevation data are available through the internet (http://hydrosheds.cr.usgs.gov). Raw SRTM elevation data includes void or holes ranging from one pixel to regions of $500 \mathrm{~km}^{2}$ [13]. The existence of no-data in the SRTM-DEM can causes significant problems during derivation of hydrological products, which require continuous flow surfaces [14]. Therefore DEM should be free from voids or holes. Most void areas of SRTM elevation data have been edited and filled in the HydroSHEDS version. However, for some areas voids are still present [15]. In January 2009 Advanced Spaceborne Thermal Emission and Reflection Radiometer (ASTER) global DEM version 1 was released. Three years later, in October 2011, ASTER-GDEM version 2 released with significant improvement in quality. The ASTER-GDEM is a joint product developed and made available to the public by the Ministry of Economy, Trade, and Industry (METI) of Japan and the NASA. It is generated from data collected from the ASTER, a spaceborne earth observing optical instrument. The data are available through the internet (http://gdem.ersdac.jspacesystems.or.jp). ASTER elevation data [16]. Hendricks et al. [17] used SRTM for estimation of channel slope in Amazon watershed. A comprehensive study was conducted by Jarvis et al. [12] to evaluate the SRTM data against the cartographic DEM derived from topo maps at scale 1:50000 for Honduras areas. Tulu [18] assessed the suitability of SRTM-DEM for runoff studies and compared with ASTER-DEM. He observed that daily runoff output of SWAT model when ASTER-DEM was used is higher than when the SRTM-DEM was used. Hancock et al. [19] used 90 meter SRTM elevation data for drainage network and hydrologic modelling. They have found that 90

m SRTM data results in incorrect drainage network patterns and different runoff properties compared to DEM with a high resolution of $10 \mathrm{~m}$. Osorio et al. [20] compared ASTER and SRTM DEMs with DEM derived from topo map at scale of 1:50000 for watershed delineation. In theory, the DEM resolution should be selected as a function of the land surface features, the scale at which the processes are modeled, and numerical models used to model the process [10].

\section{ClassificAtion of Natural HaZARds}

A widely accepted definition characterizes natural hazards as "those elements of the physical environment, harmful to man and caused by forces extraneous to him." More specifically, in this document, the term "natural hazard" refers to all atmospheric, hydrologic, geologic, and wildfire phenomena that, because of their location, severity, and frequency, have the potential to affect humans, their structures, or their activities adversely. Among the natural hazards and possible disasters to be considered are:

$$
\begin{aligned}
& \text { - Earthquakes } \\
& \text { - Volcanic Eruptions } \\
& \text { - Tsunami } \\
& \text { - Landslides } \\
& \text { - Subsidence }
\end{aligned}
$$

Natural Hazards can also be divided into catastrophic hazards, which have devastating consequences to huge numbers of people, or have a worldwide effect, such as impacts with large space objects, huge volcanic eruptions, world-wide disease epidemics, and world-wide droughts. Such catastrophic hazards only have a small chance of occurring, but can have devastating results if they do occur.

Natural Hazards can also be divided into rapid onset hazards, such as Volcanic Eruptions, Earthquakes, Flash floods, Landslides, Severe Thunderstorms, Lightening, and wildfires, which develop with little warning and strike rapidly. Slow onset hazards, like drought, insect infestations, and disease epidemics take years to develop [21].

\section{A. Prediction and Warning}

Risk and vulnerability can sometimes be reduced if there is an adequate means of predicting a hazardous event.

\section{B. Prediction}

Prediction involves a statement of probability that an event will occur based on scientific observation. Such observation usually involves monitoring of the process in order to identify some kind of precursor event(s) - an anomalous small physical change that may be known to lead to a more devastating event

Forecasting

Sometimes the word "forecast" is used synonymously with prediction and other times it is not.

In the prediction of floods, hurricanes, and other weather related phenomena the word forecast refers to short-term prediction in terms of the magnitude, location, date, and time 
of an event. Most of us are familiar with weather forecasts.

In the prediction of earthquakes, the word forecast is used in a much less precise way - referring to a long-term probability that is not specific in terms of the exact time that the event will occur

\section{Early Warning}

A warning is a statement that a high probability of a hazardous event will occur, based on a prediction or forecast. If a warning is issued, it should be taken as a statement that normal routines of life should be altered to deal with the danger imposed by the imminent event.

The effectiveness of a warning depends on the timeliness of the warning, effective communications, public information systems and the credibility of the sources from which the warning came [21].

If warnings are issued too late, or if there is no means of disseminating the information, then there will not be time enough or responsiveness to the warning. If warnings are issued irresponsibly without credible data or sources, then they will likely be ignored. Thus, the people responsible for taking action in the event of a potential disaster will not respond.

This study performs flood potential mapping which can be considered as early warning natural hazard disaster.

\section{GIS TOOLS}

A GIS companion product has been used to assist in watershed boundary delineation and parametrization. The Geospatial Hydrologic Modeling Extension (HEC-GeoHMS) which is a GIS link for ArcGIS was used to extract physical parameters from DEM. The HEC-GeoHMS has been developed jointly by Hydrologic Engineer Center, Environmental Science Research Institute (ESRI) and University of Texas lead by professor Maidment. HEC-GeoHMS allows visualizing spatial information, documenting watershed characteristics, performing spatial analysis, and delineating sub-basins and streams. Working with HEC-GeoHMS through its interfaces, menus, tools, buttons allows the user to create hydrologic inputs. The current version of HEC-GeoHMS creates a background map file, lumped basin model, grid-cell parameter file, and distributed basin model. The background map file contains the stream alignments and subbasin boundaries. The lumped basin file included hydrologic elements and their connectivity to represent the movement of water through the drainage system.

\section{HEC-GEOHMS FEATURES}

\section{A. Data Management}

The GeoHMS performs numbers of administrative tasks that help the user manage GIS data derived from the program. The data management feature tracks thematic GIS data layers and their names in a manner largely transparent to the user. Prior to performing a particular operation, the manager will offer the appropriate thematic data inputs for operation, and prompt the user for conformation. Other times, the data management feature manages the locations of various projects and also performs error checking and detection [22].

\section{B. Terrain Processing}

GeoHMS allows user to perform terrain preprocessing in a step-by-step fashion or batch mode. In the step by step process, the user often has the opportunity to examine the outputs and makes corrections to the data set, as appropriate. However if the user has perform the terrain preprocessing a number of times, then batch processing will allow terrain preprocessing to be performed unattended [21]. In terrain processing, several steps is performed on raw DEM prior to watershed delineation and parametrization including filling sinks, reconditioning and smoothing.

\section{HMS Model Support}

The emphasis of the watershed delineation, processing and manipulation capability is on flexibility, ease of use, and interactivity. When the subbasin delineation process is done many smaller subbasin can be merging together or larger basin can be split at the user interest point.

\section{CASE Study}

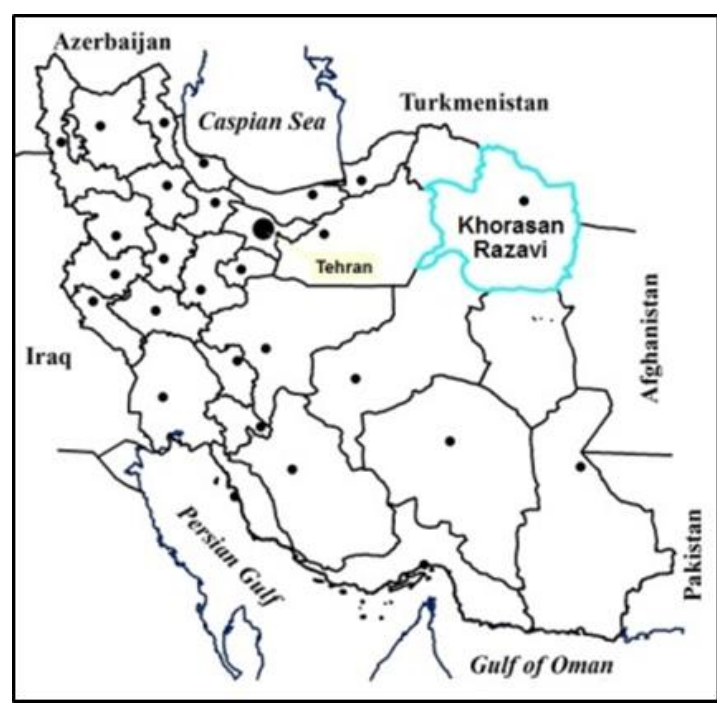

Fig. 1. Layout of the study area.

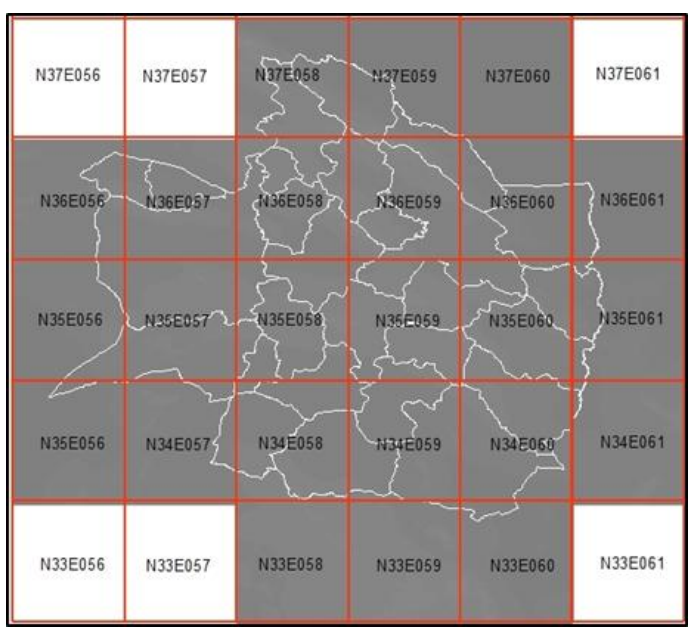

Fig. 2. Mosaic of ASTER-GDEM for the study area.

A case study was conducted to identify the flood potential zonation in Khorasan Razavi/Iran (see Fig. 1). The 
methodology is based on ASTER-GDEM data to delineate watershed boundaries. Fig. 2, demonstrate the ASTER tiles for the study area. Flood potential zonation was performed by SCS-CN method. The SCS-CN model employs the landuse and hydrologic soil group to derive Curve Number $(\mathrm{CN})$. The initial $\mathrm{CN}$ values were adjusted with the terrain slope derived from the optimized ASTER-GDEM (see Fig. 3). Flood poetical maps were generated based on 1 hour frequency storm with return period of 25 years. This period is sufficient to recover the flood damages by the local insurance companies. To account the maximum flood potential for the study area, $\mathrm{CN}$ values were calculated for wet condition. And initial abstraction ratio was considered to be 0.005 .

Final flood potential map was classified in five quantitative classes (see Fig. 4).

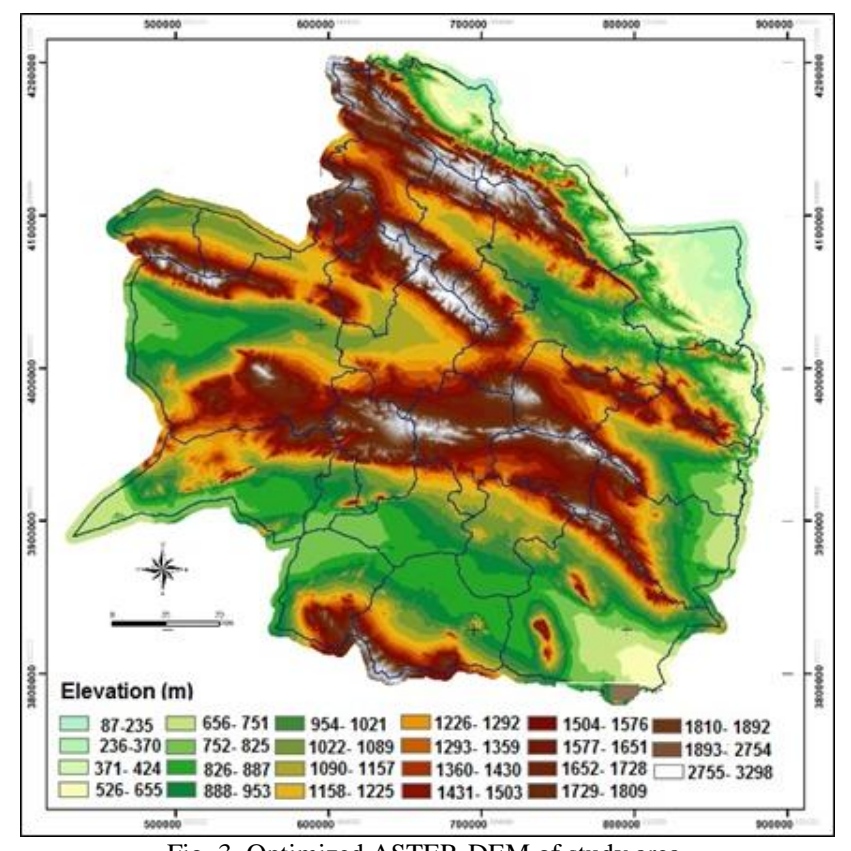

Fig. 3. Optimized ASTER-DEM of study area.

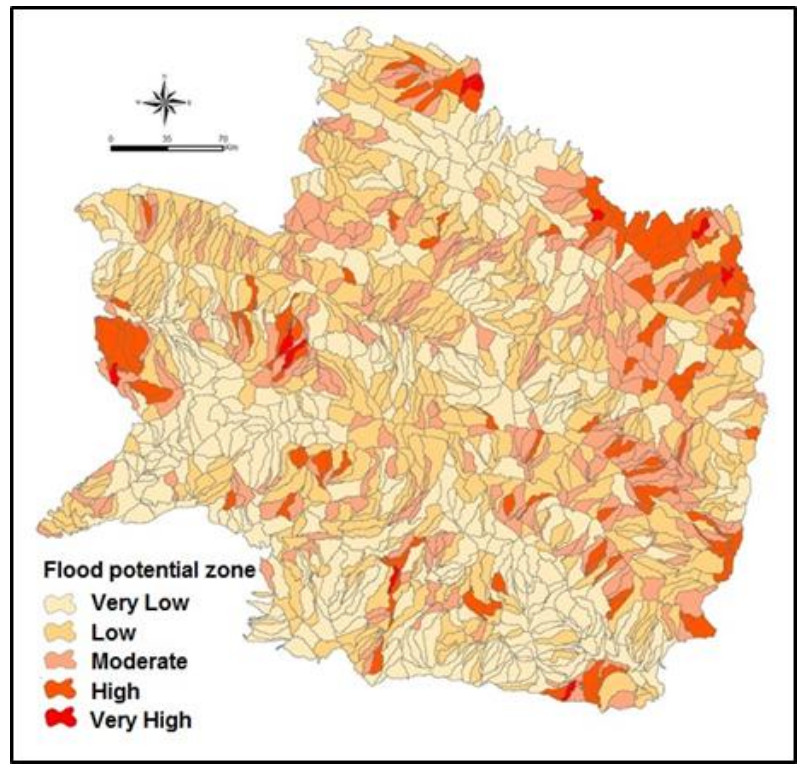

Fig. 4. Subbasin scale flood potential zonation in the study area.

\section{CONCLUSION AND REMARKS}

Digital elevation model is one of the main inputs in Geohazard studies specifically in semi and fully distributed hydrological modelling. Cell size is a key characteristic of the DEM which denote its capability for spatial modelling. Recently, rapid growth of earth observation technology has facilitated Geohazard researches. Particularly, public domain DEMs provide valuable information for different areas of research and studies. By using satellite DEM data it is possible to study flood potential zonation, flood inundation mapping, landslide susceptibility, snowmelt modelling and many other Geohazards effectively. Using satellite data eliminates institutional bureaucracy, access to data at the border of neighboring countries, edge matching and code consistency. The satellite DEM data is easy to access and very cost effective.

\section{REFERENCES}

[1] UN-ISDR. (2014). Terminology of disaster risk reduction. United Nations International Strategy for Disaster Reduction. [Online]. Available: http://www.unisdr.org/we/inform/terminology

[2] C. J. Westen, Remote Sensing and GIS for Natural Hazards Assessment and Disaster Risk Management, Dehradun, India, pp. 307-375, May 2012

[3] C. Miller and R. Laflamme, The digital terrain model: theory and applications, Photogrammetric Engineering, vol. 24, pp. 433-442, June 1958.

[4] D. Maidment, "GIS and hydrologic modeling," Environmental modeling with GIS, pp. 147-167, Apr. 1993.

[5] D. Djokic and Z. Ye, Hydrologic and Hydraulic Modelling Support with Geographic Information Systems, 2000, pp. 65-84.

[6] B. Vieux, Distributed Hydrologic Modeling Using GIS, Kluwer Academic Publishers, 2004, ch. 3, pp. 56-59.

[7] Z. Li, C. Zhu, and C. Gold, Digital Terrain Modeling: Principles and Methodology, 1st ed., UK: CRC press, 2010, ch. 3, pp. 136-139.

[8] S. Wu, J. Li, and G. Huang, "A study on DEM-derived primary topographic attributes for hydrologic applications: Sensitivity to elevation data resolution," Applied Geography, vol. 28, no. 3, pp. 210-223, May 2008.

[9] D. R. Maidment, "GIS and hydrologic modeling - An assessment of progress," presented at the Third International Conference on GIS and Environmental Modeling, Santa Fe, New Mexico, 1996.

[10] D. R. Maidment and D. Djokic, Hydrologic and Hydraulic Modeling Support: With Geographic Information Systems, 1 ed., vol. 1, New York: ESRI Press, 2000.

[11] J. Garbrecht and L. W. Martz, Digital Elevation Model Issues in Water Resources Modeling, in Hydrologic and Hydraulic Modeling Support: With Geographic Information Systems, New York: ESRI Press, 2000.

[12] A. Jarvis et al., "Practical use of SRTM data in the tropics: comparisons with digital elevation models generated from cartographic data," Working Document, vol. 198, pp. 32-34, 2004.

[13] H. Reuter, A. Nelson, and A. Jarvis, "An evaluation of void-filling interpolation methods for SRTM data," International Journal of Geographical Information Science, vol. 21, no. 9, pp. 983-1008, 2007.

[14] B. Lehner, K. Verdin, and A. Jarvis, "HydroSHEDS," Technical Documentation, Washington, DC., pp. 7-8, 2006.

[15] NASA. (2005). Shattle radar topography mission. [Online]. Available: http://www2.jpl.nasa.gov/srtm/contact.htm

[16] Z. Yu, "Grid-spacing effect on watershed hydrological simulations," Journal of Hydrologcal Science \& Technology, vol. 13, pp. 75-85, 1997.

[17] G. Hendricks et al., Channel Slope from SRTM Water Surface Elevations in the Amazon Basin, 2003.

[18] M. D. Tulu, "SRTM-DEM suitability in runoff studies," International Institute for Geo-information Science abd Earth Observation, ITC: Enschede. pp. 96-99, 2005.

[19] G. R. Hancock et al., "A comparison of SRTM and high-resolution digital elevation models and their use in catchment geomorphology and hydrology: Australian examples," Earth Surface Processes and Landforms, vol. 31, pp. 1394-1412, 2006.

[20] J. Osorio et al., "Comparison of watershed boundaries derived from SRTM and ASTER digital elevation datasets and from a digitized topographic map," 2007.

[21] Natural_Disasters. [Online]. Available: http://www.tulane.edu/ sanelson/Natural_Disasters/introduction.htm 
[22] J. Doan, "Geospatial hydrologic modeling extension HEC-GeoHMS-user's manual-version 1.0," Davis, California, 2000.

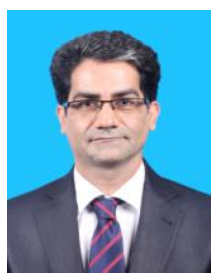

Abolghasem Akbari was born in Gonabad, Iran in May 1966. He got his degree in civil engineering in Feb. 2001 and the master degree in applied geoinformatics from University of Twente, the Netherlands in March 1988. He defended his Ph.D. thesis entitled: "GIS-based flood modeling using Hydrological model and remotely sensed data" in Dec 2011 and graduated from the Department of Civil Engineering, University Malaya, Malaysia. He is an expert in HydroGIS and has done many research and projects and published more than 25 journal papers and conference proceedings. Currently he is an assistant professor in Faculty of Civil Engineering and Earth Resources, University Malaysia Pahang.

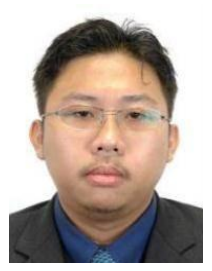

Noram Irwan Bin Ramli was born in Johor Bahru, Malaysia in May 1982. He got his diploma in civil engineering (building services \& maintenance) from University Technology MARA (UiTM) in Feb 2004 and the B.Eng. in civil engineering, from University Technology MARA (UiTM) in Dec. 2006. He has got his master in structural engineering, from University Science Malaysia (USM) in Oct. 2008. He has strong background in academic research with special interest in wind engineering. Currently he is a Ph.D. candidate in University Science Malaysia.

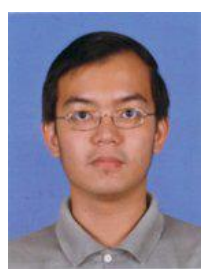

Ngien Su Kong was born in Sarawak, Malaysia in June 1982. He got his degree in civil engineering from University Technology Malaysia (UTM) in Mar. 2006. $\mathrm{He}$ received his MSc degree in water engineering with distinction from Cardiff University in Feb. 2008. He defended his Ph.D. thesis entitled: "Experimental and numerical analysis of non-aqueous phase liquids migration in double-porosity subsurface systems" in May 2012 in Faculty of Civil Engineering University Technology Malaysia He has a strong background in environmental modeling and published more than 20 journal papers and conference proceeding. Currently he is an assistant professor in Faculty of Civil Engineering \& Earth Resources, University Malaysia Pahang. 